\title{
Clinical Characteristics and Surgical Treatment of Esophageal Spinal Metastasis - A Single Center 10-year Retrospective Study
}

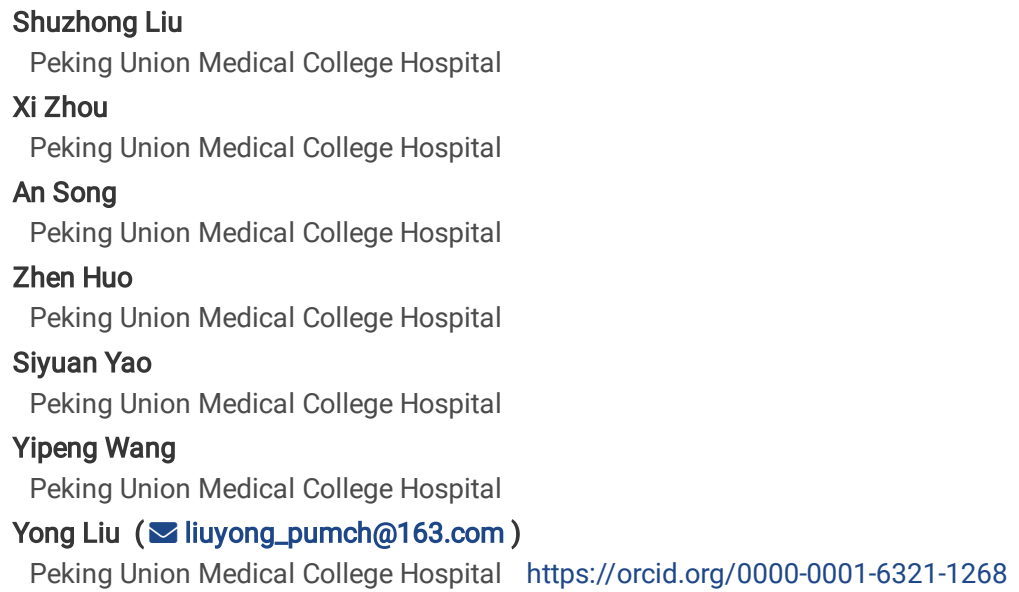




\section{Abstract}

Objective:Our research aims to discuss the clinical characteristics, treatment methods, and prognostic characteristics of patients with esophageal cancer spinal metastasis. It is one of the largest clinical studies on the disease to date. The purpose is to improve clinicians' understanding of the clinical features and prognosis of esophageal spine metastases and share our experience in dealing with this entity.

Methods: Six patients with spinal metastasis due to esophageal cancer who had received surgical treatment at the bone tumor center of Peking Union Medical College Hospital from January 2010 to January 2020 were selected. The clinical data, surgical records, imaging examinations, pathological reports, and immunohistochemical results of all patients were reviewed by the team. In the study, we applied two surgical treatments, namely open surgery and percutaneous vertebroplasty. Radiotherapy, chemotherapy, and targeted therapy were used as adjuvant treatments. Retrospective analysis of the patient's basic clinical data was done.

Results:All six patients with metastatic spinal esophageal cancer (MSEC) were male with an average age of $58.0 \pm 5.3$ years. The average duration between the esophageal cancer resection and diagnosis of spinal metastases was 24.8 (2-72) months. Of the six patients, four had spinal metastases located in the thoracic spine and two had metastases located in the lumbar spine. We referred to the revised Tokuhashi score and Tomita score to recommend individualized surgical treatment plans for patients, and fully respected the patients' wishes. All six patients underwent surgical treatment, a total of six operations, including four percutaneous vertebroplasty and two open surgery. After the operations, the symptoms of the patients improved significantly. During the follow-up, all six patients died of the disease with the average time from spinal surgery to death being $8.8 \pm 3.7$ months.

Conclusions: In general, patients with esophageal cancer spine metastases have a poor prognosis, and the average survival time of these patients often does not exceed 12 months. The combination of surgical treatment and postoperative adjuvant therapy can control symptoms effectively and improve the patient's quality of life.

\section{Introduction}

More than half the world's cases of esophageal cancer (EC) are found in China, which has the highest morbidity and mortality rates for this cancer in the world [1-3]. Metastasis to important organs such as lung and liver is commonly found in esophageal cancer, but the clinical occurrence of metastatic spinal esophageal cancer (MSEC) is often neglected by clinicians. To date, there have been few reports of spinal metastases in EC and clinical treatments for esophageal spine metastases are limited [4,5]. MSEC seriously affects the quality of life of these patients, and even cause severe bone-related events with serious consequences.

In order to gain a deeper understanding of the clinical biological characteristics and prognostic factors of MSEC, we have collected and summarized the clinical data of six patients with MSEC admitted to the bone tumor team of Peking Union Medical College Hospital within the last 10 years. Of the more than 1,000 patients with spinal metastases that have been surgically treated in our single center over the past 10 years, only six of these patients originated from malignant esophageal tumors. Here we report the results of our analysis.

\section{Materials And Methods}

Six patients with spinal metastases from primary esophageal cancer who had undergone surgical treatment in our department from were selected from patients treated between January 2010 to January 2020. Postoperative pathological examinations confirmed the final diagnosis of MSEC. The clinical data and surgical records, imaging features, and pathology reports of all these patients were reviewed. The final follow-up was completed in May 2020 . This study was approved by the ethics committee of our hospital and the informed consent of the participants was obtained.

All six patients underwent primary esophageal tumor resection before admission and were diagnosed with esophageal cancer by postoperative pathology. The diagnosis of spinal metastatic esophageal cancer was confirmed by the following three criteria: (1) imaging findings on X-ray, computed tomography (CT), magnetic resonance imaging (MRI), bone scan or fluorodeoxyglucose (FDG) and positron emission tomography computed tomography(PET/CT) that are consistent with MSEC; (2) a previous history of esophageal cancer; (3) final diagnosis by examination of the pathological specimen of the primary tumor biopsy or open surgery. The preoperative neurological status was classified according to the Frankel score and the ASIA injury classification. The quality of life of all patients was evaluated by the Karnofsky score, the ECOG score, and the VAS scoring system. Surgery made through individualized plans was performed by the surgical team led by Professor Liu. The SINS system was used to assess the stability of the spine, and the revised Tokuhashi and Tomita scoring systems were used to initially assess the patient's prognosis and assist in the development of surgical procedures.

All patients were recommended to undergo surgical treatment after a comprehensive evaluation, and six of them ultimately received spinal surgery, with a total of six operations. Surgical indications included: (1) initial definition of spinal metastases with unbearable pain or neurological deficits; (2) inability of conservative treatment to achieve satisfactory control of the spinal lesions; (3) an absence of no clear contraindication for surgery after detailed evaluation by various sub-specialized departments; (4) pre-operative preparation in accordance with the opinions of thoracic surgery and anesthesiology; (5) proven suitability of patients for surgical intervention according to their general condition; (6) willingness and motivation of patients and their families for the surgery. According to the location and scope of spinal tumors and the general condition of the patients, an individualized surgical strategy was adopted for each patient. Adjuvant treatment recommendations are also needed after the operation according to the individual condition of the patient.

Radiological assessments (X-ray, CT, or MRI) was performed regularly at three and six months after surgery, and at regular intervals every six months during the follow-up. For patients showing tumor progression, PET/CT is recommended for further evaluation. Follow-up data was obtained from outpatient visits and telephone interviews. During the follow-up of postoperative conditions, the neurological function and quality of life were reassessed according to the VAS 
score, Frankel scoring system, and the Karnofsky scoring system. The follow-up period is defined as the time interval from the date of spinal surgery to the date of death or until the last follow-up.

\section{Results}

\section{Clinical characteristics}

The clinical information and surgical data of the six patients are shown in Table 1. Of these six patients, all were male. The average age was $58.0 \pm 5.3$ years (range 51-67 years). All six patients had a history of surgery for primary lesions of esophageal cancer. The average duration between esophageal cancer resection and diagnosis of spinal metastatic cancer was 24.8 (2-72) months. One patient had liver metastasis, one patient had pleural metastases, and the other four had no bone or organ metastases except for spinal lesions. After the surgery for primary tumors, three patients received postoperative radiotherapy and chemotherapy, one patient received only radiotherapy, one patient received chemotherapy combined with Nimotuzumab, and one patient did not receive adjuvant therapy.

Table 1

Clinical characteristics of 6 patients with metastatic esophageal cancer of spine in our single centre

\begin{tabular}{|c|c|c|c|c|c|c|c|c|c|c|}
\hline Patients & $\begin{array}{l}\text { Year of } \\
\text { operation }\end{array}$ & $\begin{array}{l}\text { Age } \\
\text { (y), } \\
\text { sex }\end{array}$ & $\begin{array}{l}\text { Symptoms } \\
\text { and signs }\end{array}$ & $\begin{array}{l}\text { Spinal } \\
\text { metastases } \\
\text { location }\end{array}$ & $\begin{array}{l}\text { Incomplete } \\
\text { paralysis } \\
\text { or } \\
\text { paralysis }\end{array}$ & $\begin{array}{l}\text { Resection } \\
\text { of } \\
\text { primary } \\
\text { lesion }\end{array}$ & Surgery & $\begin{array}{l}\text { Adjuvant } \\
\text { treatment }\end{array}$ & $\begin{array}{l}\text { Postop } \\
\text { complications }\end{array}$ & $\begin{array}{l}\text { Progressiol } \\
\text { free survivi } \\
\text { (month) }\end{array}$ \\
\hline 1 & 2014 & $51, \mathrm{M}$ & $\begin{array}{l}\text { Low back } \\
\text { pain, } \\
\text { incomplete } \\
\text { paralysis }\end{array}$ & T12 & $\begin{array}{l}\text { Acute } \\
\text { incomplete } \\
\text { paralysis }\end{array}$ & Yes & $\begin{array}{l}\text { Dorsal En-bloc, } \\
\text { reconstruction } \\
\text { of vertebral } \\
\text { body with } \\
\text { titanium cage } \\
\text { and bone } \\
\text { cement, } \\
\text { instrumentation }\end{array}$ & None & None & 7 \\
\hline 2 & 2016 & $67, \mathrm{M}$ & Back pain & T100T11 & No & Yes & $\begin{array}{l}\text { Percutaneous } \\
\text { vertebroplasty }\end{array}$ & $\begin{array}{l}\text { Radiation } \\
\text { therapy }+ \\
\text { chemotherapy }\end{array}$ & None & 10 \\
\hline 3 & 2017 & $58, \mathrm{M}$ & Back pain & T11 & No & Yes & $\begin{array}{l}\text { Percutaneous } \\
\text { vertebroplasty }\end{array}$ & $\begin{array}{l}\text { Radiation } \\
\text { therapy }\end{array}$ & None & 3 \\
\hline 4 & 2018 & $58, \mathrm{M}$ & $\begin{array}{l}\text { Low back } \\
\text { pain }\end{array}$ & L5 & No & Yes & $\begin{array}{l}\text { Percutaneous } \\
\text { vertebroplasty }\end{array}$ & $\begin{array}{l}\text { Radiation } \\
\text { therapy }+ \\
\text { chemotherapy }\end{array}$ & None & 11 \\
\hline 5 & 2018 & $59, \mathrm{M}$ & $\begin{array}{l}\text { Weakness } \\
\text { and } \\
\text { numbness } \\
\text { of bilateral } \\
\text { lower } \\
\text { limbs, } \\
\text { complete } \\
\text { paralysis }\end{array}$ & Т3ロT4ロT5 & $\begin{array}{l}\text { Acute } \\
\text { complete } \\
\text { paralysis }\end{array}$ & Yes & $\begin{array}{l}\text { Posterior } \\
\text { decompression, } \\
\text { tumor } \\
\text { resection, bone } \\
\text { cement } \\
\text { augmentation } \\
\text { as well as T1- } \\
\text { T7 internal } \\
\text { fixation }\end{array}$ & $\begin{array}{l}\text { Chemotherapy } \\
+ \\
\text { Nimotuzumab }\end{array}$ & None & 2 \\
\hline 6 & 2018 & $55, \mathrm{M}$ & Back pain & L2 & No & Yes & $\begin{array}{l}\text { Percutaneous } \\
\text { vertebroplasty }\end{array}$ & $\begin{array}{l}\text { Radiation } \\
\text { therapy }+ \\
\text { chemotherapy }\end{array}$ & None & 9 \\
\hline
\end{tabular}

All the patients had progressive local pain before surgery. At the time of admission, one patient had complete paralysis of both lower extremities, one patient had incomplete paralysis of both lower extremities, and the remaining four patients were able to walk. The average duration of preoperative symptoms was $4.0 \pm 3.0$ months (range from 1 to 9 months). The locations of the spinal metastasis were in the thoracic spine in four cases and the lumbar spine in two cases. The scoring data of the six patients with spinal metastases are shown in Table 2 . The imaging findings are similar to those of other spinal metastatic tumors characterized by osteolytic destruction. Osteolytic lesions can be observed in all six patients andin one case these were also accompanied by osteogenic changes. The tumor is usually not accompanied by a large paravertebral soft tissue mass. MRI showed iso-hypointensity on the T1-weighted image and iso-hyperintensity on the T2-weighted image. The tumor was significantly enhanced on enhanced MRI. There were four cases of a single metastasis in the spine (Figure 1) and two cases of multiple metastases in the spine (Figure 2). 
Table 2

Clinical data of spinal metastasis in 6 patients with metastatic spinal esophageal cancer in our single centre

\begin{tabular}{|c|c|c|c|c|c|c|c|c|c|c|c|c|}
\hline Patients & $\begin{array}{l}\text { Year of } \\
\text { operation }\end{array}$ & $\begin{array}{l}\text { Age } \\
\text { (v), } \\
\text { sex }\end{array}$ & $\begin{array}{l}\text { Bone } \\
\text { change }\end{array}$ & $\begin{array}{l}\text { Spinal } \\
\text { compression }\end{array}$ & $\begin{array}{l}\text { Paravertebral } \\
\text { expansion }\end{array}$ & $\begin{array}{l}\text { Visceral } \\
\text { metastasis }\end{array}$ & $\begin{array}{l}\text { ECOG } \\
\text { score }\end{array}$ & $\begin{array}{l}\text { SINS } \\
\text { score }\end{array}$ & $\begin{array}{l}\text { KPS } \\
\text { score }\end{array}$ & $\begin{array}{l}\text { Frankel } \\
\text { score }\end{array}$ & $\begin{array}{l}\text { ASIA } \\
\text { score }\end{array}$ & $\begin{array}{l}\text { Revised } \\
\text { Tokuha } \\
\text { score }\end{array}$ \\
\hline 1 & 2014 & $51, \mathrm{M}$ & $\begin{array}{l}\text { Osteolytic } \\
\text { type }\end{array}$ & Yes & No & No & 4 & 16 & 30 & D & $\mathrm{C}$ & 7 \\
\hline 2 & 2016 & $67, \mathrm{M}$ & $\begin{array}{l}\text { Osteolytic } \\
\text { type }\end{array}$ & No & No & No & 1 & 11 & 70 & E & $E$ & 9 \\
\hline 3 & 2017 & $58, \mathrm{M}$ & $\begin{array}{l}\text { Mixed } \\
\text { type }\end{array}$ & No & No & No & 2 & 13 & 40 & E & $E$ & 8 \\
\hline 4 & 2018 & $58, \mathrm{M}$ & $\begin{array}{l}\text { Osteolytic } \\
\text { type }\end{array}$ & No & No & No & 1 & 8 & 80 & E & $E$ & 10 \\
\hline 5 & 2018 & $59, \mathrm{M}$ & $\begin{array}{l}\text { Osteolytic } \\
\text { type }\end{array}$ & Yes & Yes & Hepatic metastasis & 4 & 12 & 20 & $A$ & $A$ & 2 \\
\hline 6 & 2018 & $55, \mathrm{M}$ & $\begin{array}{l}\text { Osteolytic } \\
\text { type }\end{array}$ & No & No & Pleural metastasis & 2 & 8 & 80 & E & $E$ & 10 \\
\hline
\end{tabular}

All the surgical treatments were completed by our departmental team headed by Professor Liu; all members of the team had at least five years of professional training. A total of six operations were performed, with two patients undergoing posterior tumor resection, spinal cord decompression, and internal fixation. The average blood loss during the operations was 1100 (1000-1200) ml. Four patients underwent minimally invasive percutaneous vertebroplasty with bone cement, and the average blood loss during these operations was 25 (20-30) ml. No obvious complications occurred during the perioperative period, and the original adjuvant treatment strategy was continued after the operations. All six patients received bisphosphonate treatment after surgery. Postoperative immunohistochemical results all supported the pathological diagnosis of MSEC.

\section{Follow-up}

The average follow-up time was $8.8 \pm 3.7$ months (range: $3-12$ months). Local spinal tumor progression was found in six patients (100\%) after the initial spinal surgery in our center, with an average progression-free survival of $7.0 \pm 3.7$ months (range: $3-12$ months). All six patients (100\%) died of the diseaseduring the follow-up visits, with an average overall survival time of $8.8 \pm 3.7$ months (range: 3-12 months). After surgery, the patients' local pain symptoms all improved significantly. In the assessment at one week after surgery, the neurological conditions showed an improvement of 1-2 gradeson theFrankel score. No obvious complications occurred during the perioperative period.

\section{Discussion}

MSEC is not very rare in clinical practice, but because of the poor prognosis of patients, it is often not paid enough attention [1-3]. Theliterature contains only a few case reports. Its low incidence and concealment make it difficult for clinicians to determine appropriate treatment strategies and prognosis.

The mechanism by which esophageal cancer metastasizes to the axial skeleton is presumed to be related to the cancer's anatomical characteristics [6,7]. The esophageal vein merges into the azygos vein and hemiazygous vein. The azygos vein and hemiazygous vein are extensively connected to the intercostal and vertebral vein systems, and the spinal venous system is lacking. The blood flow in this venous system is slow and when the pressure in the thoracic and abdominal cavity is increased, the tumor embolus in the thoracic and abdominal cavity can enter the vertebral venous system directly without passing through the lung and liver, allowing it to transfer to the vertebrae and to colonize and proliferate to form a metastatic tumor. In addition, the esophagus is adjacent to the thoracic vertebrae allowing easy transfer of cancer cells. Our research also shows that these metastases are more frequent in the thoracic spine, which supports this hypothesis.

It has been reported that the peak time of bone metastasis of esophageal cancer is within one year after the primary lesion resection, and the incidence rate decreases after one year [4,5,8,9]. About half of the cases have multiple lesions [1-3]. Goodner et al reported 100 patients with bone metastases from esophageal cancer [10]. The survival time of patients with a single bone metastasis was about 3.1 months, and the survival time of patients with multiple bone metastases was about 1.5 months [10]. In this study, there were cases with four single lesions, accounting for $66.7 \%$, and two cases with multiple lesions, accounting for $33.3 \%$. No metastasis to other organs was seen in the four patients with single spinal lesions. After active surgical treatment, both the patients' quality of life and the prognosis were significantly improved. In the literature, the longest survival time was reported to be up to 12 months [1-3]. Studies have shown that isolated, single-site bone metastases that are not accompanied by metastases to other organs can survive for up to 12 months after active treatment, with a good prognosis [1-3,11]. This shows that surgical treatment is an effective method to improve the quality of life and prolong the survival of MSEC patients.

For MSEC patients with severe pain or neurological deficits, surgery is the fastest and most effective treatment option [12,13]. Due to the poor prognosis of MSEC, the main surgical methods in this study include two cases that underwent open surgery and four cases that underwent percutaneous vertebroplasty. We found that esophageal cancer spinal metastases have heavy blood flow during the operation, which is consistent with its imaging features. They usually show osteolytic changes, may be associated with vertebral compression fractures, and are not accompanied by paravertebral soft tissue masses, so 
percutaneous vertebroplasty with bone cement to reconstruct spinal stability may have potential advantages for improving the quality of life of patients. The main symptom of spinal metastasis is back pain, which requires analgesic and hormonal symptomatic treatment. The results are often short-lived and ineffective. Traditional surgical procedures are highly invasive in nature and the surgery itself brings more complications [1-3,12-15]. In contrast, bone cement has the potential to inhibit tumor growth and percutaneous vertebroplasty is a potentially powerful tool for the treatment of esophageal cancer spinal metastases.

Life expectancy is an important factor in deciding whether to treat surgically [12-15]. In general, if the life expectancy is between three and six months, nonsurgical treatment is usually recommended. The scoring systems proposed by Tokuhashi and Tomita emphasize the importance of the primary tumor type for prognostic assessment to distinguish surgical indications for patients with different scores [16,17]. However, the revised Tokuhashi score and Tomita score are not completely applicable to all possible situations of a specific tumor, creating potential difficulties for clinicians in making correct clinical decisions. There are certain inaccuracies in the spine tumor scoring systems currently used with the result that the clinical decision for surgery cannot rely solely on a particular scoring system. Other factors must also be considered, including how to perform a reasonable evaluationofspinal metastasis from a specific malignant tumor.

Adjuvant therapies for MSEC include palliative radiotherapy, chemotherapy, and bisphosphonate [12-19]. The purpose is to control local lesions, reduce pain, prevent fractures, and improve quality of life. Bone pain is the most prominent clinical symptom in these patients. Because squamous cell carcinoma is highly sensitive to radiotherapy, local palliative radiotherapy results in rapid relief of bone pain, with good effects and few adverse reactions [18,19]. Radiotherapy is well tolerated bya majority of patientsand is still an important treatment to control bone pain. The National Comprehensive Cancer Network guidelines recommend functional status scores for patients with esophageal cancer who cannot tolerate surgery. Only patients with a KPS score of $\geq 60$ points and/or an Eastern Cancer Cooperative Group score of $\leq 2$ points are given chemotherapy; in other cases, only the best supportive treatmentis used [20]. After radiotherapy and chemotherapy, the patient's tumor load is reduced, the pain is relieved, and the improvement of psychological and physiological conditions can benefit the patient's survival [18-20]. In our study, three patients received postoperative combined radiotherapy and chemotherapy after esophageal cancer surgery, one patient received only radiotherapy, one patient received chemotherapy combined with Nimotuzumab, and one patient declined further adjuvant therapy.

Bisphosphonate is the first-line treatment for most patients with osteoporosis and is effective for reducing the risk of fractures in the spine, pelvis and other non-spinal bones[21]. All six patients in this study received bisphosphonate therapy. However, the exact efficacy of bisphosphonate therapy in MSEC patients is not clear due to the limited number of cases and the lack of detailed clinical observations.

Patients with bone metastases have a significantly increased risk of skeletal-related events (SRES), and the occurrence of SRE is significantly related to a reduction in patient survival time [22]. Clinically, SREs such as pathological fractures and spinal cord compression caused by spinal metastasis, pain, cauda equina syndrome, and paraplegia seriously affect the quality of life in these patients. Additional problems such as pneumonia, deep vein thrombosis, pulmonary embolism, and pressure ulcers caused by long-term bed rest may greatly shorten the survival time of patients [1-3,22,23]. Our results also show that pathological fractures and spinal cord compression can affect the prognosis of MSEC patients. Complete paralysis or incomplete paralysis before spinal surgery often indicates a poor prognosis.

This study nevertheless has several limitations. Firstly, the number of cases is too small for more accurate and detailed statistical analysis to assess prognostic factors. Secondly, this study is a single-center retrospective analysis. The accuracy and practicability would need to be tested by a larger sample of data. It is the goal of this institution and other medical institutions to practice, continue to improve, and to offer accurate guidance for future clinical work. In addition, only esophageal cancer patients with spinal metastasis who had received spinal surgery within a 10 year period at a single center were included in this study, and patients with MSEC who had received only non-surgical treatment were not included, which could cause a certain selective bias in the conclusions. Despite the inclusion of only six MSEC cases this case study constitutes the first clinical series reported on MSEC, and is based on a retrospective analysis of more than 1,000 patients underwent spine surgery in a single center in the past 10 years. This specific focus on the comprehensive treatment and prognosis of MSEC will help improve the clinical management of this disease, help reduce the rate of perioperative complications and maximize the survival time of these patients.

\section{Conclusions}

Although spinal metastases from esophageal cancer are not uncommon in clinics, clinicians often do not pay enough attention to them. The prognosis of esophageal cancer patients is not good, and blindly insisting on conservative treatment is likely to delay surgery for spinal metastases, causing irreparable, serious, and even life-threateningconsequences. In short, patients with MSEC have a poor prognosis. Surgical treatment combined with postoperative adjuvant therapy is the first choice for patients. Even if surgical intervention is performed, the average survival time of these patients is still no more than 12 months. It is recommended that palliative care be used mainly to control symptoms. For patients with uncontrolled pain or neurological deficits, tumor resection and decompression surgery still need to be considered.

In summary, with the prolonged survival time of esophageal cancer patients in recent years, the incidence of spinal metastases has gradually increased, and sufficient attention should be paid to their early diagnosis and treatment. Bone scan should be routinely performed at the initial diagnosis of esophageal cancer, and, especially in diagnoses with lymph node metastasis, clinicians should be highly vigilant for spine and other bone metastases. Patients with spinal metastases should be actively managed as necessary, to control the continued development of metastases and the emergence of new metastases, and should be monitored closely after surgery to reduce patients' pain and reduce the occurrence of pathological fractures and other related complications.

\section{Abbreviations}


EC: Esophageal cancer; MSEC: Metastatic spinal esophageal cancer; CT: Computed tomography; MRI: Magnetic resonance imaging; FDG:

Fluorodeoxyglucose; PET/CT: Positron emission tomography computed tomography; KPS: Karnofsky performance score; SINS: Spinal instability score; VAS: Visual analog score; SRE: skeletal-related event

\section{Declarations}

\section{Acknowledgements}

We would like to thank our colleagues at the Departments of Thoracic surgery, Anesthesiology, Pathology, Nuclear medicine, Radiology, and Orthopaedic surgery for their support.

\section{Authors' contributions}

SZL wrote the paper. SZL, XZ, ZH, and SYY collected the data. SZL, AS, and ZH analyzed the collected data for patients. XZ and YL performed the operations. YL and YPW revised the manuscriptfor important intellectual content and technical details. All authors have read and approved the finalmanuscript. We confirm that all of us have met the criteria for authorship asestablished by the ICMJE.

\section{Funding}

This study was supportedby Peking Union Medical College GraduateStudent Innovation Fund (2018) (Project No. 2018-1002-02-08; Grant recipient: S.L.). The funder had no role in study design, data collection and analysis, decision to publish, or preparation of the manuscript.

\section{Availability of data and materials}

The anonymized data used and/or analyzed during the current study areavailable from the corresponding author on reasonable request.

\section{Ethics approval and consent to participate}

This study was approved by the Ethics Committee of Peking Union Medical College Hospital. Informed consent for the surgical procedureswas obtained from each patient.

\section{Consent for publication}

Consent for publication was obtained from each patient.

\section{Competing interests}

The authors declare that they have no competing interests.

\section{Author details}

${ }^{1}$ Department of Orthopaedic Surgery, Peking Union Medical College Hospital, Peking Union Medical College and Chinese Academy of Medical Sciences, Beijing, China.

${ }^{2}$ Department of Endocrinology, Key Laboratory of Endocrinology, National Health and Family Planning Commission, Peking Union Medical College Hospital, Chinese Academy of Medical Science \& Peking Union Medical College, Beijing, People's Republic of China.

${ }^{3}$ Department of Pathology, Peking Union Medical College Hospital, Chinese Academy of Medical Science \& Peking Union Medical College, Beijing, China.

\section{References}

1. [1] Quint LE, Hepburn LM, Francis IR, et al.Incidence and distribution of distant metastases from newly diagnosed esophageal carcinoma. Cancer. 1995;76:1120-5.

2. [2] Ozawa S, Tachimori Y, Baba H, et al. Comprehensive registry of esophageal cancer in Japan, 2002.Esophagus. 2010;7:7-22.

3. [3] Pennathur A, Gibson MK, Jobe BA, et al. Esophageal carcinoma. Lancet. 2013;381:400-412.

4. [4] Yasuaki Nakajima, Shunsuke Ohta, Takuya Okada, et al. Osteoplastic Bone Metastasis in Esophageal Squamous Cell Cancer: Report of a Case. Surg Today. 2012;42(4):376-81. 
5. [5] Assunta Grillo, Raffaella Capasso, Angelica Petrillo, et al. An Intramedullary "Flame" Recognized as Being an Intramedullary Spinal Cord Metastasis From Esophageal Cancer. J Radiol Case Rep. 2019;13(7):14-20.

6. [6]Bosch A, Frias Z, Caldwell WL, et al. Autopsy findings in carcinoma of the esophagus. Acta Radiol Oncol. 1979;18:103-12.

7. [7] Mandard AM, Chasle J, Marnay J, et al. Autopsy findings in 111 cases of esophageal cancer. Cancer. 1981;48:329-35.

8. [8]Nakamura, K, Watanabe, M, Nagai, Y. et al. Cervical intramedullary spinal cord metastasis from esophageal cancer.IntCancConf J. $2014 ; 3: 161164$.

9. [9] Dalkilic T, Tymchak Z, Kindrachuk M, et al.Intramedullary spinal cord metastasis from primary esophageal carcinoma. Canadian Journal of Neurological Sciences/Journal Canadien Des Sciences Neurologiques.2015;42(S1):S47-S47.

10. [10] Goodner JT, Turnbull AD. Bone metastases in cancer of the esophagus. Am J Roentgenol Radium Ther Nucl Med. 1971;111:365-367.

11. [11] Li SH, Huang YC, Huang WT, et al. Is there a role of wholebody bone scan in patients with esophageal squamous cell carcinoma. BMC Cancer. 2012;12:328.

12. [12] Zhang J, Wang R, Liu S, et al. Refinement of minimally invasive esophagectomy techniques after 15 years of expe rience. $J$ Gastrointest Surg. 2012;16(9):1768-1774.

13. [13] Xiao ZF, Yang ZY, Liang J, et al. Value of radiotherapy after radical surgery for esophageal carcinoma: a report of 495 patients. Ann Thorac Surg. 2003;75(2):331-336.

14. [14] Cunningham D, Allum WH, Stenning SP, et al. Perioperative chemotherapy versus surgery alone for resectable gastroesopha geal cancer. N Engl $\mathrm{J}$ Med. 2006;355(1):11.

15. [15] Ando N, lizuka T, Ide H, et al. Surgery plus chemotherapy compared with surgery alone for localized squamous cell carcinoma of the thoracic esophagus: a japan clinical oncology group study-jcog9204. J Clin Oncol. 2003;21(24):4592-4596.

16. [16] Tokuhashi Y, Matsuzaki H, Oda H, et al $₫ \mathrm{~A}$ revised scoring system for preoperative evaluation of metastatic spine tumor prognosis. Spine. 2005;30(19):2186-2191.

17. [17] K Tomita, N Kawahara, T Kobayashi, et al. Surgical Strategy for Spinal Metastases. Spine (Phila Pa 1976). 2001;26(3):298-306.

18. [18] Xiao ZF, Yang ZY, Liang J, et al. Value of radiotherapy after radical surgery for esophageal carcinoma: a report of 495 patients. Ann Thorac Surg. 2003;75:331-336.

19. [19] Gebski V, Burmeister B, Smithers BM, et al. Survival benefitsfrom neoadjuvant chemoradiotherapy or chemotherapy inoesophageal carcinoma: a meta-analysis. Lancet Oncol.

20. 2007;8(3):226-234.

21. [20]Lv J, Cao XF, Zhu B, et al. Long-term efficacy of perioperativechemoradiotherapy on esophageal squamous cell carcinoma.World J Gastroenterol. 2010;16:1649-1654.

22. [21] Zaporowska-Stachowiak I, Łuczak J, Hoffmann K, et al. Managing metastatic bone pain: New perspectives, different solutions. Biomed Pharmacother. 2017;93:1277-1284.

23. [22] Bhowmik D, Song X, Intorcia M, et al. Examination of burden of skeletal-related events in patients naive to denosumab and intravenous bisphosphonate therapy in bone metastases from solid tumors population. Curr Med Res Opin. 2019;35(3):513-523.

24. [23] Curtin M, Piggott RP, Murphy EP, et al. Spinal Metastatic Disease: A Review of the Role of the Multidisciplinary Team. Orthop Surg. 2017;9(2):145-151.

\section{Figures}



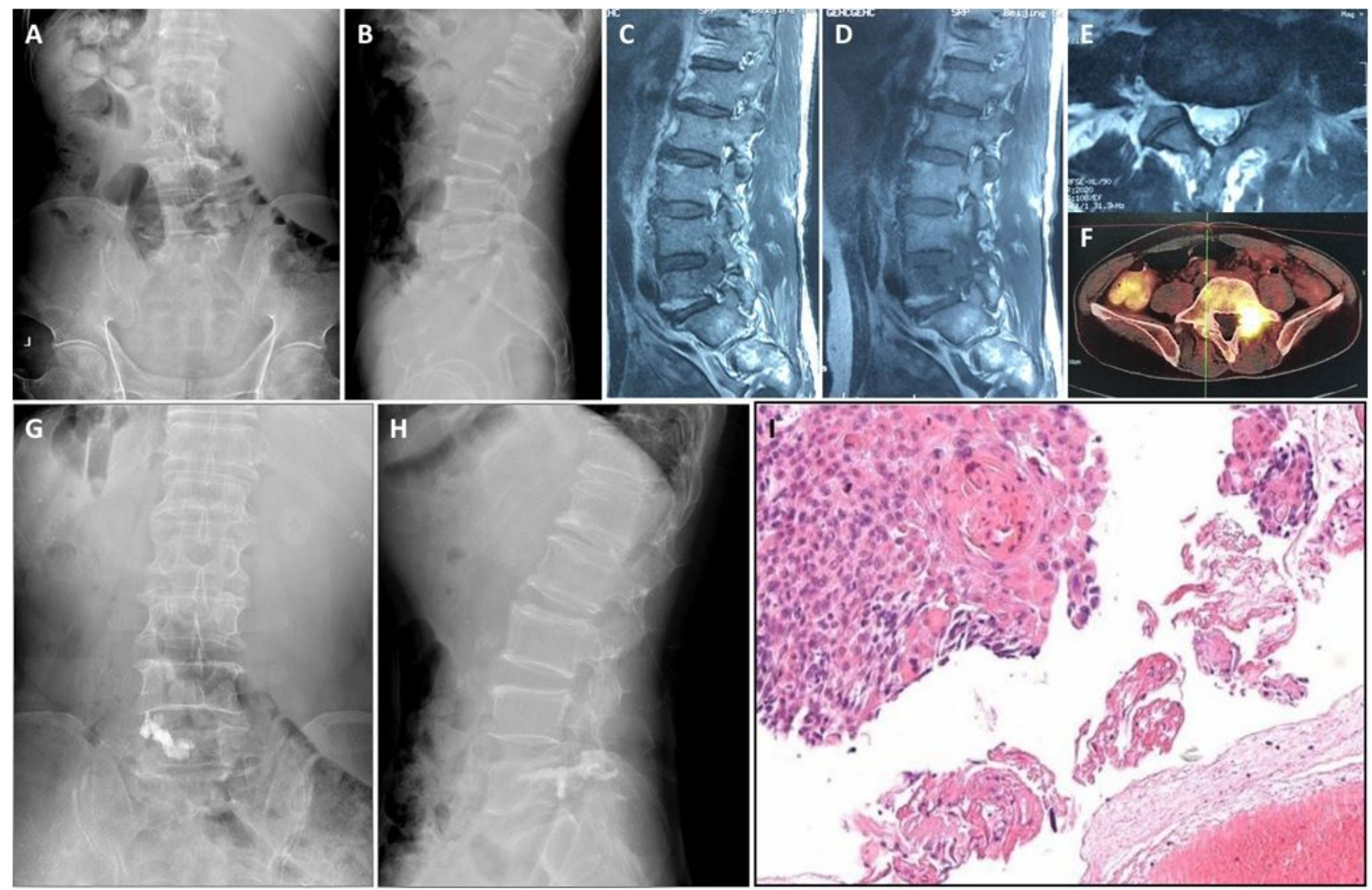

\section{Figure 1}

Radiographic and pathological images of a representative 58-year-old male patient (Case \#4). (A,B) Preoperative X-rays. (C-E) Preoperative sagittal and transverse MRI revealing vertebral metastases of L5. (F) Positron emission tomography-computed tomography revealing metastases of $L 5$. (G,H)X-ray images of the lumbar spine obtained postoperatively. (I) Microphotography showing characteristic nests of tumor cells. 

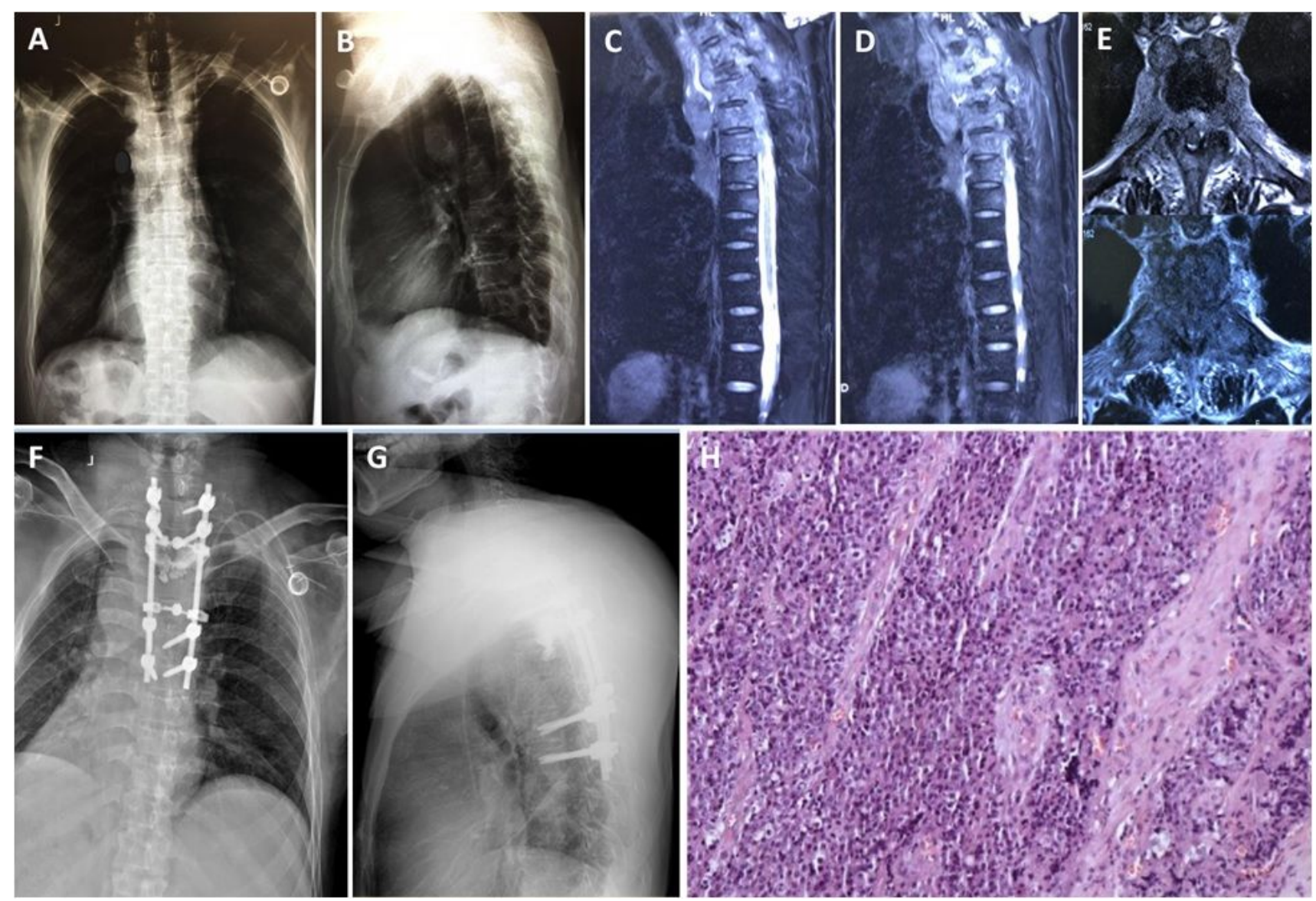

\section{Figure 2}

Radiographic and pathological images of a representative 59-year-old male patient (Case \#5). (A,B) Preoperative X-rays. (C-E) Preoperative sagittal T2weighted MRI scan revealing multiple vertebral metastases. $(F, G)$ Postoperative X-rays of the thoracic spine. (H) Microphotography showing significant nuclear pleomorphism with prominent nucleoli (H\&E). 